\title{
Can weight loss reverse polycystic ovary syndrome?
}

\author{
W. Grira ; H Zoubeidi ; H Sfar; L Ben Salem ; I.Kammoun ; C.Ben Slama \\ Department of Endocrinology and Metabolism, National Institute of Nutrition, Tunis, Tunisia
}

\section{Introduction}

Weight loss is a mainstay in the treatment of polycystic ovary syndrome (PCOS). While the cause of this complex endocrine disorder remains unknown, it's approved that weight loss improves symptoms of PCOS. We report a case of a patient with PCOS. Her symptoms disappeared totally after losing $50 \mathrm{~kg}$.

\section{Case report:}

A 16-year-old girl presented for evaluation of obesity and spaniomenorrhoea evolving since menarche.

- Physical examination :

-Weight: $88 \mathrm{~kg}$, Height:1,53m BMI: $37.5 \mathrm{~kg} / \mathrm{m}^{2}$

-Waist circumference: $85 \mathrm{~cm}$

-BP: $110 / 80 \mathrm{cmHg}$

-Pubertal stage: Tanner 5

-No clinical signs of Cushing syndrome

-No signs of hyperandrogenism

-No acanthosis nigricans

- Biology:

- Fasting blood glucose: $5 \mathrm{mmol} / \mathrm{l}$

- Oral glucose tolerance test: normal

-Serum lipid profile: Total cholesterol: $4,02 \mathrm{mmol} / \mathrm{I}$

-TG: $1,2 \mathrm{mmol} / \mathrm{I} \quad H D L c: 0,92 \mathrm{mmol} / \mathrm{I} \quad$ LDLc: $0,99 \mathrm{~g} / \mathrm{I}$

- hormone blood tests:

- LH: 15UI/I (VN : 4 -11):

-Testosterone : $2,2 \mathrm{nmol} / \mathrm{l}(\mathrm{VN}: 0,34-2) \quad$ Slightly increased

-Prolactine: $638 \mathrm{UI} / \mathrm{I}$ (VN : $40-530)$

- FSH: 5,9UI/I (VN : 4 -10)

-17OH progesterone: $0,69 \mu \mathrm{g} / \mathrm{I}$

-DHEAS: $281 \mathrm{ug} / \mathrm{dL}$

- TSH: $3,02 \mu \mathrm{UI} / \mathrm{I} \quad$ FT4:18,7pmol//

\section{- Pelvic ultrasound:}

- Bilateral polycystic ovaries.

- Normal ovarian size of 7,1 ml (right) and $5 \mathrm{ml}$ (left)

The diagnosis of PCOS is made according to Rotterdam consensus criteria (oligoanovulation and sonographic grounds) after exclusion of other etiologies, such as congenital adrenal hyperplasia, Cushing syndrome and androgen secreting tumour.

\section{- Treatment:}

-She was evaluated by a nutritional therapist and given lifestyle advice to reduce weight and increase physical activity.

-To improve her glucose tolerance, Metformin1.7 g/day (850 mg*2) was started .

\section{-Evolution: \\ $\mathrm{BMI} \mathrm{kg} / \mathrm{m}^{2}$}

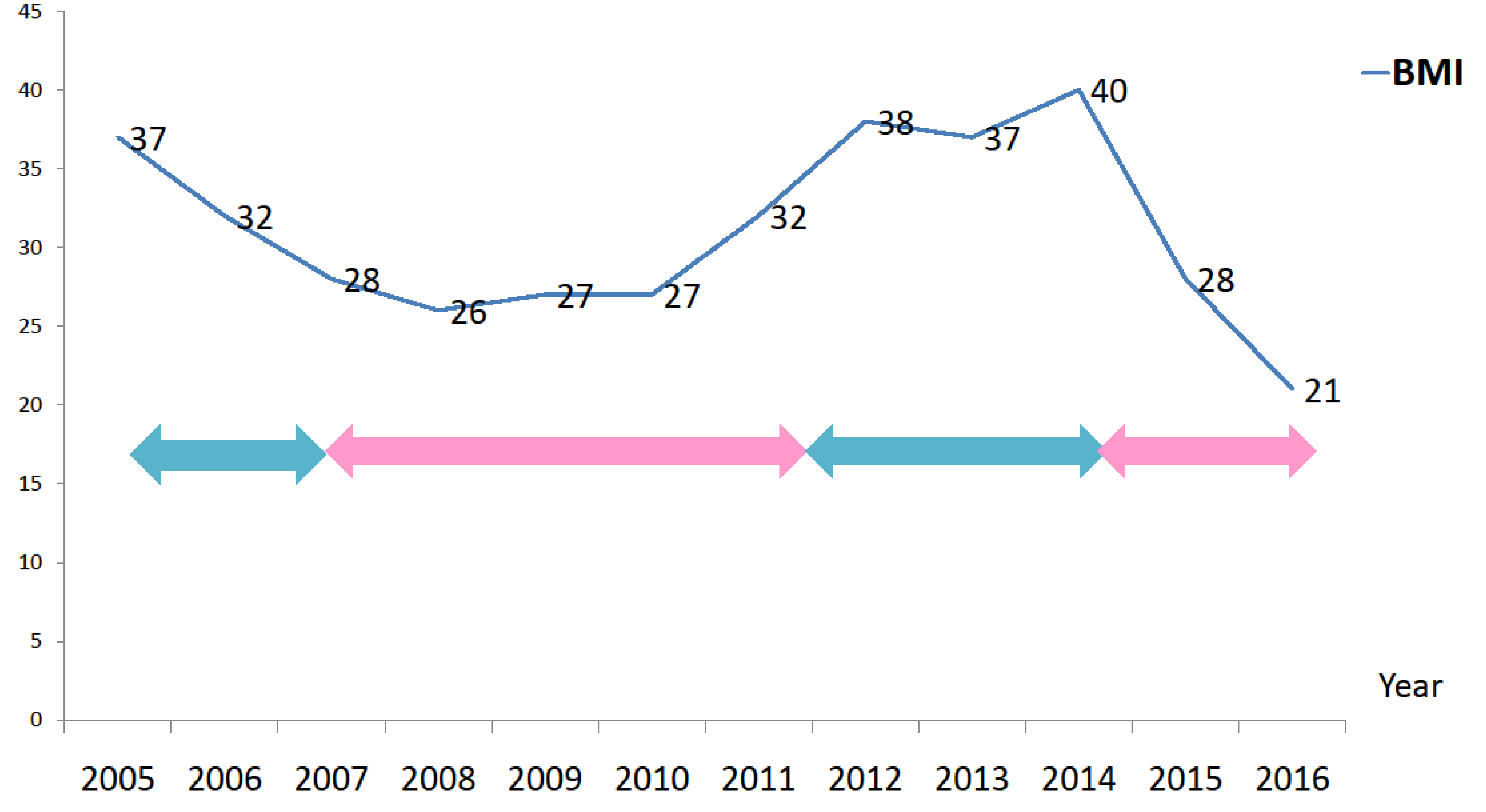

$20052006 \quad 20072008 \quad 200920102011 \quad 2012 \quad 2013 \quad 2014 \quad 2015 \quad 2016$

\section{Discussion:}

-PCOS is common in adolescents and should be considered in an adolescent with irregular menses and excess weight.

Oligomenorrhoea in adolescents is not always a stage in the physiological maturation of the hypothalamic-pituitaryovarian axis but an early sign of PCOS.

Sonographic assessment is limited by the exclusive use of the suprapubic route.

-After 2 years on metformin-diet our patient had $24 \%$ decrease in $\mathrm{BMI}$, menses were normal without progesterone medication during 3 years. But thereafter the patient no longer followed life style rules, she gained weight to $102 \mathrm{~kg}$ in 3 years (BMI:40 Kg/m²), spanioamenorhea reappeared. Lifestyle changes and metformin therapy were reapplied. Now, 2 years after lifestyle changes and metformin therapy, the patient weights $52 \mathrm{~kg}$ (BMI: $21 \mathrm{~kg} / \mathrm{m}^{2}$ ). She has normal ovulatory cycles.

-Yo-yo dieting effect should be considered in our patient: the diet is initially successful in weight loss but is unsuccessful in maintaining the loss long-term.

\section{Conclusion}

Our case illustrates the close relationship between overweight and PCOS. Therefore, lifestyle changes should be the first-line intervention in these patients, especially in presence of obesity. 